\title{
Adaptation to Climate Change in Preindustrial Iceland
}

\author{
By Matthew A. Turner, Jeffrey S. Rosenthal, Jian Chen, and Chunyan Hao *
}

We investigate the effect of climate change on population growth in 18th and 19 th century Iceland. We find that a year $1^{\circ} \mathrm{C}$ cooler than average drives down population growth rates by $0.57 \%$ in each of the next two years, for a total effect of $1.14 \%$. We also find that 18th and 19th century Icelanders adapt to prolonged changes in climate: these adaptations take about 20 years and reduce the short run effect of an annual change in temperature by about $60 \%$. Finally, we find that a $1^{\circ} \mathrm{C}$ sustained decrease in temperature decreases the steady state population by $10 \%$ to $26 \%$.

Our analysis rests primarily on two types of data. The first is annual population data dating back to 1734 . The second is imputed annual temperature data dating back to the late 1600's. We construct these data from measured temperature data and annual records of the ratio of the concentration of Oxygen-18 to Oxygen-16 in ice core strata from nearby Greenland.

The resulting long time series of population and annual temperature data allow an explicit analysis of short run and long run responses to climate change. These data also allow an analysis of the way Icelanders adapt to climate change.

We say that Icelanders 'adapt' to a

* Turner: Department of Economics, University of Toronto, 150 Saint George Street, Toronto, Ontario, Canada M5s 3G7. Email: mturner@chass.utoronto.ca. Supported in part by SsHRC. Rosenthal: Department of Statistics, University of Toronto, 100 Saint George Street, Toronto, Ontario, Canada M5s 3G3. Email: jeff@math.toronto.edu. Supported in part by NSERC. Chen: Department of Statistics, University of Toronto, 100 Saint George Street, Toronto, Ontario, Canada M5S 3G3. Email: jchen@ustat.toronto.edu. Hao: Department of Statistics, University of Toronto, 100 Saint George Street, Toronto, Ontario, Canada M5s 3G3. Email: c.hao@utoronto.edu. We thank Dwayne Benjamin, Gillian Hamilton, John Munro and Gunnar Karlsson, and seminar participants at the University of Toronto for helpful comments and discussions. We also thank Benjamin Schachter and Rebecca Lindstrom for excellent research assistance. change in climate if the same event elicits a different short run response when it follows one history than when it follows another. Our data allow a direct statistical test of this commonsense notion of adaptation. Specifically, we check whether a short run climate shock has a different effect when it follows a cold history than when it follows a warm history. By repeating this test for different definitions of 'shock' and 'history', we trace out the rate of adaptation and the time-frame over which it occurs.

\section{Data}

To learn about short and long run responses to climate change we require data satisfying three conditions. They must describe a period long enough to observe climate change. They must be at a high enough frequency to describe short run responses. They must allow us to distinguish the relationship between climate and population from confounding trends.

During the 18th and 19th century, migration to and from Iceland was rare and was actively discouraged by government policy (Karlsson, 2000). Over the period 1801-1860, when the population level was about 50,000, mean net migration was -17 people/year (Statistics Iceland, 2010). Moreover, Iceland was remarkably insulated from technical progress (Eggertsson, 1994). During the 18th and early 19th century, there was little manufacturing. Roads allowing wheeled carts were not built until nearly 1900 (Karlsson, 2000). In 1801, Reykjavik had a population of only 307 and only about $10 \%$ of calories consumed in 18th century Iceland were derived from fish (Karlsson, 2000).

In sum, 18th and 19th century Iceland was overwhelmingly employed in raising livestock and the hay to feed them, and was as insulated from migration and technolo- 
gical progress as can be hoped.

It follows that data describing Icelandic climate and population during this period should reveal a relationship if one exists, and that we can reasonably expect to distinguish this relationship from population trends caused by technological progress and migration.

Estimates of Iceland's population are available back to the middle ages (see e.g. Steffensen (1963)). However, prior to 1734 these estimates are speculative or sporadic. We restrict attention to the population data available from the annual surveys provided by Statistics Iceland (2010) from 1734 to the present.

Our estimations rely on the period ending in 1860 . We have three reasons for choosing this terminal date. First, the rapid 20th century increase in Iceland's population level was only beginning at this time. Second, a plot of the data shows no trend in the population growth rate during this period. Third, the estimated effect of climate on the population growth rate is robust to the inclusion of a quadratic in time and to changing the end of the study period to 1820 or 1880 . We conclude that for a study period ending in 1860 we are unlikely to confound the effects of latent technological change with the effect of climate on population.

We note that Iceland was subject to two catastrophic decreases in population during our study period. The earlier of the two occurred from 1756 to 1758 and was the result of a volcanic eruption which poisoned pasture land and led to famine. The second, which occurred from 1784 to 1786, was the result of plague (Karlsson, 2000). Testing indicates that the precise choice of which years to control for is not important, but controlling for these two catastrophes does improve the accuracy of our estimations. Thus, throughout the paper, our population data consists of the Statistics Iceland annual population survey results from 1734-1860, excluding 1756-1758 and 17841786.

We take the "true" Icelandic temperature to be the average of the measured temperatures at the four mainland weather stations which record temperatures from the late 1800's onward (Goddard Institute for Space Studies, 2010), i.e. at Akureyri, Reykjavic, Stykkisholmur, and Teigarhorn. Our analysis, however, requires temperature data pre-dating available measured temperatures.

We impute historical temperatures from heavy-oxygen delta ice core values, $\delta^{18} O$. Heavy-oxygen delta ice core values measure fractional deviation of the ratio of the concentration of Oxygen-18 to Oxygen-16 in ice core strata as compared to that in standard mean ocean water. Since this isotope ratio varies systematically with temperature, and since ice core strata can be accurately dated, ice core $\delta^{18} O$ is widely used as a proxy for historical temperatures.

Ice core data are not available within Iceland. However, there are four long-term ice core data sets available from nearby Greenland; Crete, Millicent, Camp Century, and Dye2 (National Climatic Data Center, 2010). We predict measured temperature as a function of contemporaneous and lagged $\delta^{18} O$ values from the four ice core series. We then use these estimates to impute temperatures to 18 th and 19th century Iceland using the much longer ice core time series. Our preferred imputation of historical annual mean temperatures is based on the isotope ratio series from the Crete icecore. Turner et al. (2010) provides more detail.

\section{Notation and estimation strategy}

We begin with notation to describe population change and climate.

Our outcome variable is annual percentage population change,

$$
(\Delta p o p)_{t}:=\frac{\text { pop }_{t+1}-p o p_{t}}{p o p_{t}} \times 100 \%,
$$

where $\operatorname{pop}_{t}$ is thousands of total population recorded on January 1 in year $t$.

We denote the current year's estimated average temperature by temp $p_{t}$, the previous year's temperature by temp $p_{t-1}$, and $k$ th lag of temperature by temp $p_{t-k}$. We also investigate the effects of moving averages of previous years' temperatures, e.g., 
MA $_{t}:=\frac{1}{2}\left(\right.$ temp $_{t-1}+$ temp $\left.p_{t-2}\right)$, or more generally,

$$
\operatorname{MA}_{t}:=\frac{1}{j}\left(t e m p_{t-1}+\ldots+t e m p_{t-j}\right) .
$$

We also consider lagged moving average temperatures:

$\operatorname{MA} j_{t-i}:=\frac{1}{j}\left(t e m p_{t-i-1}+\ldots+t e m p_{t-i-j}\right)$.

To ease exposition, we "demean" all temperature variables by subtracting off their mean over the entire extended time range 1730-1880.

We estimate variants of the following equation,

$$
\begin{array}{r}
(\Delta \text { pop })_{t}=A_{0}+f\left(\operatorname{temp}_{t}, . ., \text { temp }_{t-50}\right) \\
+ \text { Controls }+\epsilon_{t}
\end{array}
$$

where $f$ is a function of temperature variables that varies across specifications and may include lagged values, moving averages, lagged moving averages, or interaction terms.

To control for possible confounding trends our estimations include time and its square, time $e^{2}$ as control variables, where time is defined as year - 1734. To allow for effects of current population on population growth (e.g. due to resource constraints), we also control for pop $_{t}$. To account for unmeasured slowly-changing latent variables, e.g., a high percentage of women of child-bearing age, which create similarities between $\Delta$ pop for adjacent years, we control for the previous year's percentage growth, $(\Delta p o p)_{t-1}$.

By estimating equation (2) we hope to learn the nature of $f$, the function that describes the relationship between climate and population growth rates. Table 1 presents several estimates of this equation. Table 1 presents only estimations with Newey-West corrected errors. In Turner et al. (2010) we conduct extensive specification and robustness tests of the estimates presented here.

\section{Short-Term Temperature Effects}

In column 1 and 2 of table 1 we estimate equation (2) using short run measures of climate. In column 1 we consider only the previous two years, MA $2_{t}$. This leads to a highly significant coefficient $(p<0.01)$ with value 1.143 . This means that if the temperature increases by $1^{\circ} \mathrm{C}$ for one year, then in each of the two subsequent years the population growth rate will increase by $0.572 \%$, for a total effect of $1.143 \%$. If we instead use $\mathrm{MA}_{t}$ or MA $10_{t}$ as in columns 2 and 3 , then the regression coefficients are not significantly different from zero.

Taken together, regression results for MA $2_{t}$, MA $_{t}$ and MA10 $t$ suggest that a one year warm shock drives up the population growth rate during the two years following the shock, after which the effect attenuates. This basic intuition is confirmed by a distributed lag model (not shown), which is like columns $1-3$ of table 1 but includes the first six lags of temp instead of moving averages.

From table 1 we also see that current population, pop $_{t}$ is significant and negative. This confirms and quantifies our intuition that the population of Iceland is constrained by its resource base.

These results suggests a way to understand the effects of climate on Iceland's steady state population. If we assume that the population is in equilibrium (i.e., that $\left.(\Delta p o p)_{t} \equiv 0\right)$, or otherwise returns to the same value of $(\Delta p o p)_{t}$, then table 1 column 1 implies that the quantity

$$
1.143 \mathrm{MA}_{t}-0.0885 \text { pop }_{t}
$$

should be approximately constant. Given this, a little arithmetic shows that if the temperature suddenly and persistently decreased by $\delta$ degrees Celsius then the implied steady state decrease in population would be $12,915 \delta$. So, if $\delta=1$ (i.e. there is a one degree temperature decrease), then this would cause a drop of about 13,000 people, which for the population sizes we are considering in our data (i.e. around 50,000 people) represents about $26 \%$ of the population. 
TABle $1-$ Nine REgRessions (ONE PER COLumn) PREDiCting $(\Delta p o p)_{t}$.

\begin{tabular}{|c|c|c|c|c|c|c|c|c|c|}
\hline & (1) & (2) & (3) & (4) & (5) & (6) & (7) & (8) & (9) \\
\hline MA $2 t_{t}$ & $\begin{array}{c}1.143^{* * * *} \\
(0.359)\end{array}$ & & & & & $\begin{array}{c}1.153^{* * *} * \\
(0.355)\end{array}$ & $\begin{array}{c}1.133^{* * * *} \\
(0.353)\end{array}$ & $\begin{array}{c}1.084^{* * * *} \\
(0.323)\end{array}$ & $\begin{array}{c}1.104^{* * *} * \\
(0.298)\end{array}$ \\
\hline $\mathrm{MA} 5_{t}$ & & $\begin{array}{c}0.582 \\
(0.721)\end{array}$ & & & & & & & \\
\hline $\mathrm{MA} 10_{t}$ & & & $\begin{array}{c}1.172 \\
(0.971)\end{array}$ & & & & & & \\
\hline $\mathrm{MA} 10_{t-4}$ & & & & $\begin{array}{c}0.364 \\
(1.051)\end{array}$ & & $\begin{array}{c}0.485 \\
(1.017)\end{array}$ & & $\begin{array}{c}0.710 \\
(1.044)\end{array}$ & \\
\hline $\mathrm{MA} 20_{t-4}$ & & & & & $\begin{array}{l}-0.897 \\
(1.590)\end{array}$ & & $\begin{array}{l}-0.208 \\
(1.572)\end{array}$ & & $\begin{array}{l}-0.005 \\
(1.544)\end{array}$ \\
\hline $\mathrm{MA} 2_{t} \times \mathrm{MA} 10_{t-4}$ & & & & & & & & $\begin{array}{l}7.690^{*} \\
(4.454)\end{array}$ & \\
\hline $\mathrm{MA} 22_{t} \times \mathrm{MA} 20_{t-4}$ & & & & & & & & & $\begin{array}{c}11.10^{*} \\
(5.960)\end{array}$ \\
\hline pop $_{t}$ & $\begin{array}{c}-0.089^{* * * *} \\
(0.027)\end{array}$ & $\begin{array}{c}-0.091 * * * \\
(0.025)\end{array}$ & $\begin{array}{c}-0.086^{* * * *} \\
(0.026)\end{array}$ & $\begin{array}{c}-0.090^{* * *} \\
(0.025)\end{array}$ & $\begin{array}{c}-0.093^{* * *} \\
(0.026)\end{array}$ & $\begin{array}{c}-0.087^{* * * *} \\
(0.026)\end{array}$ & $\begin{array}{c}-0.089^{* * * *} \\
(0.027)\end{array}$ & $\begin{array}{c}-0.092^{* * * *} \\
(0.026)\end{array}$ & $\begin{array}{c}-0.093^{* * * *} \\
(0.028)\end{array}$ \\
\hline
\end{tabular}

Control variables in all regressions are: time, time $^{2},(\Delta p o p)_{t}$ and a constant. Newey-West standard errors in parentheses. p-values: ${ }^{* * *} \mathrm{p}<0.01,{ }^{* *} \mathrm{p}<0.05,{ }^{*} \mathrm{p}<0.1$.

Note that this calculation estimates long run changes in population on the basis of estimated responses to short run variation in weather. Given that sustained changes in climate will likely induce more adaptive responses than short run changes, we are probably overstating the effects of climate on steady state population. With this in mind, we now investigate the effects of climate over a longer time horizon.

\section{Long-Term Adaptation to Climate Change}

A natural conjecture is that ten or twenty years of unusually harsh climate impoverishes the population and causes low growth or particular susceptibility to shocks in the years immediately following. Conversely, ten or twenty years of mild climate would have the opposite effect.

To test for this sort of generalized adaptation (really maladaptation) we investigate the effect of lagged long run moving averages of climate on current population growth rates. Table 1 columns 4 and 5 indicate that there is no statistically significant effect of long-term climate histories such as MA20 $0_{t-4}$ or MA10 $0_{t-4}$ (nor MA $50_{t-4}$, not shown). Furthermore, table 1 columns 6 and 7 indicate that this non-effect persists even once short-term temperatures (from $\mathrm{MA} 2_{t}$ ) are separately taken into account. In all, the results in columns 4-7 indicate that this sort of generalized adaptation, if it oc- curs at all, has too small an effect to be measured in our sample.

We now ask whether long-term climate changes lead to specific adaptations which affect the way the population responds to short term climate shocks. This sort of specific adaptation is broadly consistent with the archeological record. Archeological evidence suggests that during cold periods Icelanders live in smaller houses, live closer to their animals, and are smaller Karlsson (2000). Each of these adaptations plausibly improves fitness under cold conditions and would probably occur over the course of a generation.

To investigate the possibility that the effect of a short run climate shock depends on the long run climate history that precedes it, table 1 columns 8-9 include not only short-term temperature shocks such as $\mathrm{MA} 2{ }_{t}$ and long-term climate changes such as $\mathrm{MA} 2 \mathrm{O}_{t-4}$, but also interactions between these two effects such as $\mathrm{MA} 2_{t} \times \mathrm{MA} 20_{t-4}$. These interaction variables allow us to investigate whether, for example, short-term temperature decreases have a larger negative effect during warm-climate periods (when the population is not well adapted to cold) than during cold-climate periods (when the population has already adapted to the cold).

Table 1 provides evidence of specific adaptation to climate. Table 1 column 8 shows that the interaction variable $\mathrm{MA} 2_{t} \times$ 
MA $10_{t-4}$ has a significant $(p<0.1)$ positive regression coefficient of 7.690. Table 1 column 9 shows that the interaction variable MA $2_{t} \times \mathrm{MA}_{20} 0_{t-4}$ has slightly larger coefficient of 11.10 with about the same level of significance. In an estimation (not shown) like those of columns 8 and 9 the interaction variable MA $2_{t} \times \mathrm{MA} 50_{t-4}$, while positive, is smaller than the ten and twenty year interaction terms and is not distinguishable from zero. This suggests that long run adaptation to climate change does occur, that this adaptation is underway way after ten years and continues for at least another ten years.

To investigate the extent to which the effects of short-term temperature shock are modified due to long-term climate change, we imagine that we begin with the climate equal to its overall mean values during our study years, so that the "demeaned" variables, MA2 and MA20, both start equal to zero. Suppose first that the short term temperature, MA2, suddenly increases by $\delta$ degrees. Then according to table 1 column 9, $\Delta$ pop would increase by the short-term shock amount

$$
S T(\delta)=1.104 \delta .
$$

If instead the overall climate persistently increased by $\epsilon$ degrees, so that both MA2 and MA20 each increased by $\epsilon$, then $\Delta p o p$ would increase by the long-term climatechange amount

$$
\begin{aligned}
L T(\epsilon) & =1.104 \epsilon-0.00492 \epsilon+11.10 \epsilon^{2} \\
& =1.09908 \epsilon+11.10 \epsilon^{2} .
\end{aligned}
$$

Now suppose that these two effects both happened, i.e. that MA20 increased by $\epsilon$ while MA2 increased by $\delta+\epsilon$. Then $\Delta p o p$ would increase by the short-long combined amount

$$
\begin{array}{r}
S L T(\delta, \epsilon)=1.104(\delta+\epsilon)-0.00492 \epsilon \\
+11.10 \epsilon(\delta+\epsilon) .
\end{array}
$$

In this scenario, the amount of this increase in $\Delta p o p$ which was due to the short-term temperature shock would be $\operatorname{SLT}(\delta, \epsilon)-$ $L T(\epsilon)$.
Hence, in this scenario, the fraction by which the effect of a short-term temperature shock has been multiplied due to the long-term climate change can be measured by

$$
\operatorname{Ratio}(\delta, \epsilon):=\frac{S L T(\delta, \epsilon)-L T(\epsilon)}{S T(\delta)},
$$

which simplifies to

$$
\operatorname{Ratio}(\delta, \epsilon)=1+10.0543 \epsilon,
$$

and in fact turns out not to depend on $\delta$.

Thus, for long run climate change $\epsilon$ in the range $\pm 0.1^{\circ} \mathrm{C}$ this ratio varies from about 0 to nearly 2 . That is, long-run climate changes could completely remove the short-term temperature shock effects (for climates about 0.1 degrees colder) or nearly double them (for climates about 0.1 degrees warmer).

In fact the standard deviation of the observed values of MA20 $t$ in our sample is only about 0.06 degrees Celsius. This is the empirical variation on which the estimates are based and thus is a reasonable value to use to evaluate the magnitude of the estimated interaction effect. For this small value of $\delta$, we find that $\operatorname{Ratio}(\delta, 0.06)=1.603258$. That is, the effect of short-term temperature shocks increases by about $60 \%$ if climate persistently warms by just $0.06^{\circ} \mathrm{C}$. On the other hand, if the climate persistently cools by $0.06^{\circ} \mathrm{C}$, $\operatorname{Ratio}(\delta,-0.06)=0.396742$, so that the effect of short-term temperature shocks decreases by about $60 \% .^{1}$

In light of the evidence for adaptation, it probably makes sense to revise the estimate of the effect of climate on steady state population from section III. On the basis of Table 1 column 9 and the discussion above, we should expect such adaptation to reduce the effects of climate on population by about $60 \%$. This suggests that we expect a long run $1^{\circ} \mathrm{C}$ temperature decrease to lead to a decrease in steady state population on the order of $(1-0.6) \times 26 \%$ or

\footnotetext{
${ }^{1}$ The standard deviation of the observed values of $\mathrm{MA} 22_{t}$ in our sample is about 0.19 degrees Celsius. However, (3) does not depend on $\delta$.
} 
about $10 \%$.

\section{Conclusion}

We investigate the effect of climate on population levels in pre-industrial Iceland. We find that short-term temperature changes affect the population growth rate. In particular, a $1^{\circ} \mathrm{C}$ decrease in temperature causes about $0.57 \%$ decrease in the population growth rate for the two subsequent years, for a total effect of $1.14 \%$. This effect appears to attenuate as the growth rate returns to trend in subsequent years. We also quantify the extent to which 18th and 19th century Icelanders adapt to long run climate change. In particular, the data suggest that long run adaptation to climate takes about 20 years and reduces the effect of cold shocks by about $60 \%$. Our results also allow us to approximate the effect of permanent climate change on steady state population levels. This approximation suggests that steady state population levels decrease by $10 \%$ to $26 \%$ for each $1^{\circ} \mathrm{C}$ of sustained adverse temperature change.

Using data on Iceland's historical GDP from Jonsson (2004), and current and historical GDP from the Penn World Tables (Heston, Summers and Aten, 2010), we estimate that Iceland's per capita GDP in 1870 was about $\$ 1436$ in 2005 us dollars. Again using the Penn World Tables, we find that 23 of the 190 countries covered in this data had per capita GDPs at or below this level in 2005. These countries account for about $5 \%$ of the population covered by the Penn world table in 2005, nearly 400 million people.

If contemporary poor agricultural populations behave like their 18th and 19th century Icelandic counterparts, then our results suggest that adverse climate change (which now refers to warming, not cooling) will have three effects. First, in the short run it will lead to a significant decrease in population growth rates. Second, over the course of a generation, adaptation will offset about $60 \%$ of the short-run effects. Finally, in the long run, we expect a decrease in steady state populations.

\section{REFERENCES}

Eggertsson, T. 1994. "No experiments, monumental disasters: Why it took a thousand years to develop a specialized fishing industry in Iceland." Journal of Economic Behavior and Organization, 30: $1-23$.

Goddard Institute for Space Studies. 2010. "Surface Temperature Analysis." Available at: http://data.giss.nasa.gov/gistemp/station_data/.

Heston, A., R. Summers, and B. Aten. 2010. "Penn World Tables." Center for International Comparisons of Production, Income and Prices at the University of Pennsylvania, August 2009.

Jonsson, G. 2004. "The Transformation of the Icelandic Economy: Industrialisation and Economic Growth, 1870-1950." Exploring Economic Growth. Essays in Measurement and Analysis. A Festschritft for Riitta Hjerppe on the 60th Birthday. Edited by Sakari Heikkinen and Jan L Luiten Van Zanden, 131-166.

Karlsson, G. 2000. The History of Iceland. Minneapolis, MN:University of Minnesota Press.

National Climatic Data Center. 2010. "Ice Core data." Available at: http://www.ncdc.noaa.gov/paleo/icecore/current.html.

Statistics Iceland. 2010. "Annual population table." Available at: http://www.statice.is/Pages/1170.

Steffensen, J. 1963. "Islands Fokemængde Gennem Tiderne." Medicinsk Forum, 129-143.

Turner, M. A., J. Rosenthal, J. Chen, and C. Hao. 2010. "Adaptation to CLimate Change: Evidence from 18th and 19th Century Iceland." Processed, University of Toronto. 